\title{
COMMENT
}

\section{Quantifying long-term risks to sea otters from the 1989 'Exxon Valdez' oil spill: Comment on Bodkin et al. (2012)}

\author{
Mark A. Harwell* , John H. Gentile \\ Harwell Gentile \& Associates, LC, PO Box 291267, Port Orange, Florida 32129-1267, USA
}

\begin{abstract}
Bodkin et al. (2012; Mar Ecol Prog Ser 447:273-287) assessed the frequency at which sea otters Enhydra lutris might encounter subsurface oil residues from the 'Exxon Valdez' oil spill. They concluded that a pathway exists for exposures of sea otters to residual oil in the intertidal zone, and imply that this pathway has delayed recovery of sea otters. We agree that the potential exposure pathway exists, and the Bodkin et al. (2012) estimates of the frequency of encountering subsurface oil residues (4 to 10 times per year) comport with our previously published studies (2 to 7 times per year). However, we disagree that this pathway constitutes a significant risk to sea otters. We discuss results from our quantitative ecological risk assessment using an individualbased model that specifically simulated this pathway of exposures to a population of 500000 sea otters. This conservative model predicted that assimilated doses of polycyclic aromatic hydrocarbons in subsurface oil residues to the 1 -in- $1000^{\text {th }}$ most-exposed sea otters would be 1 to 2 orders of magnitude below the chronic effects thresholds that we established using USEPA data and methodology. When we artificially increased the rate of encountering subsurface oil residues, it required 4 to 10 encounters per day to reach effects levels. We conclude that the subsurface oil residues from the oil spill could not plausibly be responsible for any individual- or populationlevel effect on the sea otters at northern Knight Island.
\end{abstract}

KEY WORDS: Sea otter - 'Exxon Valdez' oil spill • Ecological risk assessment - Enhydra lutris . Individual-based models

\section{Introduction}

Bodkin et al. (2012) explored the frequency at which pits that are excavated by sea otters Enhydra lutris while foraging for infaunal prey in the intertidal zone potentially could intersect subsurface oil residues (SSOR) remaining from the 'Exxon Valdez' oil spill. They concluded that infaunal foraging by sea otters in western Prince William Sound (PWS; Alaska), the distribution of sea otter pits in the intertidal zone, and the presence of SSOR in the vicinity of foraging areas demonstrate a potential pathway for

*Email: mharwell@ecologicalrisk.com sea otters to be exposed to the polycyclic aromatic hydrocarbons (PAHs) in SSOR. We reached the same conclusion in Harwell et al. (2010a).

To estimate these frequencies, Bodkin et al. (2012) reported new studies that monitored the diving patterns of sea otters near northern Knight Island (NKI; an area in PWS that was heavily oiled by the spill) using 19 time-depth recorders recovered between 2003 and 2008. Additionally, in summer 2008 they surveyed the intertidal zone of soft-sediment beaches of NKI for the presence and location of sea otter pits. Their calculations resulted in a frequency of sea

() The authors 2013. Open Access under Creative Commons by Attribution Licence. Use, distribution and reproduction are unrestricted. Authors and original publication must be credited. 
otters encountering SSOR of 10 times per year (range 2 to $24, \mathrm{n}=15$ ) for females and 4 times per year (range listed both as 2 to 4 and 2 to $5, \mathrm{n}=4$ ) for males. By comparison, the estimates of Harwell et al. (2010a; their Table 2) were about 2 to 7 times per year, depending on the sea otter class $(7$ classes of sea otters were distinguished based on age and gender); consequently, the Bodkin et al. (2012) estimates of the frequency of sea otter encounters with SSOR comport with our previously published estimates.

Thus, while we agree with Bodkin et al. (2012) about the existence of this potential exposure pathway, and while we do not dispute their methodology or their quantification of the frequency of sea otters encountering SSOR, we differ in assessing what it means simply to identify a potential pathway of exposure. We believe that this disagreement relates to an apparent misunderstanding of the concept of 'ecological risk'. Our perspectives derive from this background: We led the development of the US Environmental Protection Agency's (USEPA) ecological risk assessment framework 20 yr ago (USEPA 1992, 1998, Gentile et al. 1993), in which an exposure pathway is only the first step in characterizing ecological risk. This framework and associated guidelines have now been widely adopted throughout the federal government and in many other venues (e.g. CERN 1999, Norton et al. 2003, Cormier \& Suter 2008). We first applied it to the 'Exxon Valdez' oil spill by assessing the ecological significance of remaining risks more than 15 yr after the spill (Harwell \& Gentile 2006) following the methodology and criteria that we also developed for USEPA (Gentile \& Harwell 1998). We qualitatively assessed the oil spill risks compared with the other major anthropogenic and natural stressors impinging on the PWS-Gulf of Alaska ecosystem (Harwell et al. 2010b), we quantified the ecotoxicological risks to sea otters from remaining oil residues (Harwell et al. 2010a, 2012), and we used the ecological risk framework to assess ecological recovery of the PWS ecosystem (Harwell \& Gentile 2013, Harwell et al. 2013). Thus, our extensive experience in designing and conducting ecological risk assessments informs us that there is a great deal more to understanding risk than implied by Bodkin et al. (2012).

\section{Risks to sea otters}

Bodkin et al. (2012) implied, as the title of their article itself suggests, that the pathway for continuing exposures to SSOR has led to long-term effects on
PWS sea otters. However, having a pathway of exposure does not necessarily mean there is a significant risk; there must also be sufficient assimilated doses from the exposure pathways, as assessed against appropriate toxicity reference values, to cause ecologically significant effects. Bodkin et al. (2012) also stated that PAH exposure levels cannot be quantified, and that the biological and ecological consequences remain unknown. Again, we disagree: there is a rich history of ecological risk assessments being used to quantify exposures, project the ecological consequences, and inform ecological risk management and regulatory decision-making processes (e.g. Bartell et al. 1992, Ferenc \& Foran 2000, Suter 2007, Barnthouse et al. 2008, and most issues of the journal 'Human and Ecological Risk Assessment' since its inception in 1995).

Characterizing the risk requires these steps beyond just identifying a pathway of exposure: (1) quantitatively predicting the doses of PAHs that a sea otter would assimilate per SSOR-encountering event; (2) estimating how those doses vary over the population and from that, estimating the doses that the most-exposed sea otters would experience; (3) developing the chronic toxicity reference values (TRVs) for sea otters and the PAHs based on appropriate USEPA-approved laboratory studies and methods; (4) comparing the distribution of assimilated doses against the TRVs to derive the distribution of quantitative hazard quotients (the ratio of assimilated dose to TRV); (5) from that, assessing the distribution of predicted effects on individual sea otters; and (6) extrapolating the distribution of individual-level effects to judge the potential for effects on the at-risk subpopulation. Finally, attributing putative effects on a subpopulation of sea otters to this one pathway of exposure must not only consider that specific risk picture, but also consider the range of other stressors impinging on the subpopulation to reach a conclusion of attributable risk.

We have already followed these steps to assess this specific pathway (Harwell et al. 2010a, 2012) using an individual-based model (see DeAngelis \& Gross 1992, Munns et al. 2007) that we developed to quantify all plausible routes of PAH exposures of sea otters at NKI. The model is stochastic, capturing measured environmental variability for the parameters affecting exposures. By simulating 500000 individuals in each scenario, the variability in exposures was thoroughly characterized just as the sea otters living in the NKI environment would experience it. Many sensitivity analyses were conducted to explore effects of different model parameters, model struc- 
tures, and sources of uncertainty on results, and altogether $>1$ billion sea otter hours were simulated to capture environmental, SSOR, and sea otter variability. To provide a conservative risk assessment, we rank-ordered the assimilated doses and focused on the $99.9 \%$ quantile $\left(1-\mathrm{in}-1000^{\text {th }}\right.$ most-exposed) individuals, i.e. the sea otters who just happened to have the most SSOR encounters at the highest PAH concentrations.

The effects component of the risk assessment followed USEPA $(2005,2007)$ to establish appropriate chronic TRVs for PAH exposures. TRVs are defined as the dose from chronic exposures above which ecologically relevant effects might occur to wildlife species and below which it is reasonable to expect that such effects would not occur (USEPA 2005). We derived the no-observed-adverse-effects level (NOAEL) and lowest-observed-adverse-effects level (LOAEL) TRVs from about 40 mammalian toxicity studies in the USEPA Eco-SSL database (USEPA 2007), conservatively using the geometric $95 \%$ lower confidence limits for TRVs. Resulting exposures, characterized as assimilated doses to the 99.9\% quantile most-exposed sea otters, were estimated by our base model to be $\sim 30$ to 125 times lower than the NOAEL TRV threshold and $\sim 75$ to 310 times lower than the LOAEL threshold (the range varying across the 7 modeled classes of sea otters). None of the sensitivity analyses came within an order of magnitude of the effects thresholds on even the single-mostexposed individual in the simulated population of 500000 individuals (i.e. the $99.9998 \%$ quantile). We concluded therefore that there was no plausible risk to any individual sea otter at NKI from 'Exxon Valdez' oil residues (Harwell et al. 2010a). When we now use the version of the model that allows assignment of a specific rate of SSOR encounters, the rates estimated by Bodkin et al. (2012) result in even lower risks than projected by our base model.

We also assessed what would be required to cause population-level effects on sea otters by creating hypothetical exposure regimes of sufficient magnitude to force effects to occur (Harwell et al. 2012). Model results showed that even for the most-exposed individuals, it would take many months of continuous exposure at $\sim 4$ and $\sim 10$ pits intersecting SSOR per day for NOAEL and LOAEL TRV levels, respectively, to be reached. This rate contrasts with our base model predictions of one SSOR-intersecting pit occurring, on average, about once every 50 to $180 \mathrm{~d}$, depending on the sea otter class. This illustrates just how far the SSOR-encountering rates estimated by Bodkin et al. (2012) (4 to 10 times per year compared to 4 to 10 times per day) actually are below the rates necessary to cause any plausible effects on even the most-exposed sea otters.

We examined other quantiles of exposures, including $96 \%$, i.e. where assimilated doses to the mostexposed $4 \%$ of the population would exceed effects thresholds. That quantile matches the rationale of Bodkin et al. (2002) (that the overall western PWS population increased at a rate of $\sim 0.04 \mathrm{yr}^{-1}$ while the NKI subpopulation remained constant over an $8 \mathrm{yr}$ period [1993 to 2001] at $~ 75$ individuals) in concluding that the NKI subpopulation of sea otters continued to experience effects. That rate translates into a net absence of $\sim 3$ additional sea otters per year at NKI if that subpopulation were growing at the same rate as the total PWS population. Based on the $96 \%$ quantile results (see Fig. 3 in Harwell et al. 2012), it would require $>25$ SSOR-intersecting pits per day for such a net absence to result from SSOR toxicity, a rate that far exceeds the frequencies of 4 to 10 times per year estimated by Bodkin et al. (2012).

Bodkin et al. (2012) also presented new information on seasonality of sea otter foraging behavior, pointing out that rates may differ over the year by more than an order of magnitude between the highest $\left(24 \mathrm{yr}^{-1}\right)$ and lowest $\left(2 \mathrm{yr}^{-1}\right)$ frequencies of encountering SSOR, and suggesting that estimates that do not account for this seasonality can produce biased exposure risk. While the seasonality issue is interesting, we point out that either rate remains 2 orders of magnitude below our conservative estimates for the thresholds for effects (4 to 10 encounters per day). Thus the seasonality of foraging rates does not effectively result in any significant bias under current conditions in PWS and does not affect our conclusions.

Other data, both pre- and post-spill, on sea otter abundance at NKI and other parts of PWS are equivocal, and some authors argue that there has not been a long-term depression in sea otter subpopulation numbers at NKI caused by the oil spill (e.g. Garshelis \& Johnson 2001, 2013a, b; see also Figs. 3, 6 \& 7 in Bodkin et al. 2011 to judge the plausibility of an ongoing effect on the NKI subpopulation of sea otters, particularly when considering all data up to the present instead of only the selected $8 \mathrm{yr}$ period). However, even if one accepts Bodkin et al.'s (2002, 2012) argument that sea otters at NKI are experiencing a subpopulation-level effect, our quantitative risk assessments indicate that such an effect could not plausibly be caused by exposures to residual subsurface oil from the 'Exxon Valdez' oil spill. While we certainly understand there are uncertainties in eco- 
logical modeling (just as there are important uncertainties in laboratory and field studies), the fact that the projections from our conservative model for the highest-exposed individuals are so far below effects thresholds provides confidence in our conclusions.

\section{Attributable risks}

Bodkin et al. (2012) stated that since they established a potential pathway for SSOR exposure to sea otters, that pathway is a logical explanation for purported subpopulation effects, but this both erroneously equates exposure with risk (contrary to USEPA 1998) and erroneously presumes that 'Exxon Valdez'-derived PAH toxicity is the only stressor to consider. To the contrary, other stressors do exist in PWS (Harwell et al. 2010b). USEPA's (2010) guidance for multi-stressor environments is to establish plausible causal relationships between stressor and effects and apply abductive inference (Josephson \& Josephson 1996) to identify which hypothesis best explains the available information. USEPA (2010) follows Hill's (1965) criteria as adapted for ecological issues (Fox 1991, Beyers 1998): (1) co-occurrence - an effect occurs only where and when its cause occurs; (2) sufficiency - the causal factor should be of sufficient magnitude (e.g. intensity, frequency, duration) to produce the observed effect; (3) temporality - a cause must precede its effect; and (4) coherence the relationship between cause and effect must be consistent with scientific knowledge and theory.

In that context, consider the Bodkin et al. (2012) explanation of a putative absence of a few sea otters per year: exposure to residual PAHs from an oil spill that happened more than 2 decades previously. However, those PAHs are in mostly inaccessible, buried deposits of oil residues that occur almost solely where sea otters do not dig for clams. There are 2 reasons for this: (1) only $\sim 12 \%$ of SSOR was found to occur in the lower intertidal zone (Short et al. 2006), the only intertidal zone where sea otters actually forage for infauna (Dean et al. 2002, Bodkin et al. 2012), even though the probabilities of SSOR encounters calculated by both Short et al. (2006) and Bodkin et al. (2012) are based on the incorrect assumption that sea otters forage throughout the intertidal zone; and (2) SSOR occurred in sediments under a surface covering of stable armor composed of coarse gravel, cobble, and boulders (Hayes \& Michel 1999, Taylor \& Reimer 2008) but rarely in unarmored, finer-grained sediments (Taylor \& Reimer 2008), which is the primary clam habitat in PWS. Moreover, to cause even such a small reduction in the rate of growth of the subpopulation, sea otters would have to encounter those buried oil residues more than 25 times per day continuously for weeks or months; that rate contrasts with Bodkin et al.'s (2012) own analyses, which indicate the expected rate of SSOR encounters of 4 to 10 times per year. Thus, their proposed 'logical explanation' fails the sufficiency criterion.

Alternative hypotheses derive from the other stressors impinging on PWS that could affect sea otters. Harwell et al. (2010b) developed qualitative conceptual models of the natural and anthropogenic drivers and stressors of the PWS-Gulf of Alaska ecosystem, which showed that natural stressors truly dominate and shape this ecosystem, especially climatic and oceanographic variability (e.g. Stabeno et al. 2004, Mundy \& Olsson 2005). In particular, climate regime shifts over the past few decades have caused high variability in abundance of forage fish and many marine mammals and sea birds that depend on them (e.g. Trites et al. 2007, Overland et al. 2008, Estes et al. 2009). The relative importance of natural variability only increases over time, as natural variability remains unabated while the signal of the effects from the oil spill continuously diminishes. Thus, while the oil spill related stressors rose to the level of critical importance to the ecosystem immediately after 'Exxon Valdez', the long-term spill related stressors have become inconsequential in comparison to natural processes (Harwell et al. 2010b).

To follow one example, USFWS (2005) listed as 'threatened' the coastal Alaskan sea otter population west of but not including PWS, because the population in the region had declined by 55 to $67 \%$ since the mid-1980s, and over $90 \%$ in some areas. Estes et al. (1998) and USFWS (2005) stated that the dramatic sea otter population decline was most likely attributable to increased transient killer whale predation. This was suggested to be driven by large changes in the killer whale's prey resource base (in particular the collapse of the Steller sea lion and harbor seal populations in the western Pacific Ocean), which in turn may have been driven by climatic shifts and overfishing (e.g. NRC 2003).

Thus, as an example of an alternative hypothesis for a putative depression of NKI sea otter numbers, a single killer whale off NKI could consume a few sea otters relatively quickly (i.e. the annual net absence of 3 sea otters could occur in a single bout of killer whale feeding; see Williams et al. 2004). Indeed, 2 of the 3 attacks of killer whales on sea otters that have been directly observed occurred off NKI (Hatfield et al. 1998), and Vos et al. (2006) found 5 dead sea otters 
in the stomach of a dead killer whale in Latouche Passage, just south of Knight Island. Anthropogenic stressors also could cause effects on sea otters, such as subsistence harvesting (e.g. 5 to $10 \%$ of the Knight Island sea otter population was legally harvested by Alaskan Natives in 2000 and 2003; Garshelis \& Johnson 2013a,b), or perhaps even the extraordinarily intense sampling of sea otters at NKI over the past 2 decades, as documented in many Trustees-sponsored publications (www.evostc.state.ak.us), might have encouraged a few sea otters to seek another place to live (e.g. sea otters tend to leave areas with high boat traffic; Garshelis \& Garshelis 1984).

There are other potential causes (see Garshelis \& Johnson 2013b, Harwell \& Gentile 2013), but we do not claim that any one of these necessarily caused detectable effects on the NKI subpopulation. We do, however, assert that PAH toxicity from SSOR could not reasonably be the responsible agent. Clearly, judicious application of the USEPA (2010) stressoridentification guidance would not focus on oil spill derived PAH toxicity.

Acknowledgements. The authors acknowledge the financial support provided by Exxon Mobil Corporation for the time needed to prepare this Comment; however, the opinions and conclusions expressed herein are strictly those of the authors and do not necessarily represent the opinions of ExxonMobil.

\section{LITERATURE CITED}

Barnthouse LW, Munns WR Jr, Sorensen MT (eds) (2008) Population-level ecological risk assessment. CRC Press, Boca Raton, FL

Bartell SM, Gardner RH, O'Neill RV (1992) Ecological risk estimation. Lewis Publishers, Boca Raton, FL

Beyers DW (1998) Causal inference in environmental impact studies. J N Am Benthol Soc 17:367-373

Bodkin JL, Ballachey BE, Dean TA, Fukuyama AK and others (2002) Sea otter population status and the process of recovery from the 1989 'Exxon Valdez' oil spill. Mar Ecol Prog Ser 241:237-253

Bodkin JL, Ballachey BE, Esslinger GG (2011) Synthesis of nearshore recovery following the 1989 Exxon Valdez oil spill: trends in sea otter population abundance in western Prince William Sound. Restoration Projects 070808, 070808A, and 090808 Final Report. US Geological Survey, Alaska Science Center, Anchorage, AK

Bodkin JL, Ballachey BE, Coletti HA, Esslinger GG and others (2012) Long-term effects of the 'Exxon Valdez' oil spill: sea otter foraging in the intertidal as a pathway of exposure to lingering oil. Mar Ecol Prog Ser 447:273-287

CERN (Committee on Environment and Natural Resources) (1999) Ecological risk assessment in the Federal Government. National Science and Technology Council, Office of the White House, Washington, DC (www.epa.gov/ nscep/index.html)
Cormier SM, Suter GW II (2008) A framework for fully integrating environmental assessment. Environ Manag 42: 543-556

> Dean TA, Bodkin JL, Fukuyama AK, Jewett SC and others (2002) Food limitation and the recovery of sea otters following the 'Exxon Valdez' oil spill. Mar Ecol Prog Ser 241:255-270

DeAngelis DL, Gross LJ (1992) Individual-based models and approaches in ecology: populations, communities and ecosystems. Springer, New York, NY

Estes JA, Tinker MT, Williams TM, Doak DF (1998) Killer whale predation on sea otters linking oceanic and nearshore ecosystems. Science 282:473-476

Estes JA, Doak DF, Springer AM, Williams TM (2009) Causes and consequences of marine mammal population declines in southwest Alaska: a food-web perspective. Philos Trans R Soc Lond B Biol Sci 364:1647-1658

Ferenc SA, Foran JA (eds) (2000) Multiple stressors in ecological risk and impact assessment: approaches to risk estimation. SETAC Press, Pensacola, FL

Fox GA (1991) Practical causal inference for eco-epidemiologists. J Toxicol Environ Health 33:359-373

Garshelis DL, Garshelis JA (1984) Movements and management of sea otters in Alaska. J Wildl Manag 48:665-678

Garshelis DL, Johnson CB (2001) Sea otter population dynamics and the Exxon Valdez oil spill: disentangling the confounding effects. J Appl Ecol 38:19-35

Garshelis DL, Johnson CB (2013a) Sea otters: trying to see the forest for the trees since the Exxon Valdez. In: Wiens JA (ed) Oil in the environment: legacies and lessons of the Exxon Valdez oil spill. Cambridge University Press, Cambridge, p 348-379

> Garshelis DL, Johnson CB (2013b) Prolonged recovery of sea otters from the Exxon Valdez oil spill? A re-examination of the evidence. Mar Pollut Bull 71:7-19

> Gentile JH, Harwell MA (1998) The issue of significance in ecological risk assessments. Hum Ecol Risk Assess 4: 815-828

Gentile JH, Harwell MA, van der Schalie W, Norton S, Rodier D (1993) Ecological risk assessment: a scientific perspective. J Hazard Mater 35:241-253

> Harwell MA, Gentile JH (2006) Ecological significance of residual exposures and effects from the Exxon Valdez oil spill. Integr Environ Assess Manag 2:204-246

Harwell MA, Gentile JH (2013) Assessing risks to sea otters and the 'Exxon Valdez' oil spill: new scenarios, attributable risk, and recovery. Hum Ecol Risk Assess, doi:10.1080/ 10807039.2013.828513 (in press)

Harwell MA, Gentile JH, Johnson CB, Garshelis DL, Parker KR (2010a) A quantitative ecological risk assessment of the toxicological risks from Exxon Valdez subsurface oil residues to sea otters at Northern Knight Island, Prince William Sound, AK. Hum Ecol Risk Assess 16:727-761

Harwell MA, Gentile JH, Cummins KW, Highsmith RC and others (2010b) A conceptual model of natural and anthropogenic drivers and their influence on the Prince William Sound, Alaska, ecosystem. Hum Ecol Risk Assess 16: 672-726

Harwell MA, Gentile JH, Parker KR (2012) Quantifying population-level risks using an individual-based model: Sea otters, Harlequin Ducks, and the Exxon Valdez oil spill. Integr Environ Manage Assess 8:503-522

Harwell MA, Gentile JH, Parker KR (2013) Characterizing ecological risks, significance, and recovery. In: Wiens JA (ed) Oil in the environment. Legacies and lessons of the 
Exxon Valdez oil spill. Cambridge University Press, Cambridge, p 383-419

Hatfield BB, Marks D, Tinker MT, Nolan K, Peirce J (1998) Attacks on sea otters by killer whales. Mar Mamm Sci 14: 888-894

Hayes MO, Michel J (1999) Factors determining the longterm persistence of Exxon Valdez oil in gravel beaches. Mar Pollut Bull 38:92-101

Hill AB (1965) The environment and disease: association and causation. Proc R Soc Med 58:295-300

Josephson J, Josephson S (1996) Abductive inference. Cambridge University Press, Cambridge

Mundy P, Olsson P (2005) Climate and weather. In: Mundy PR (ed) The Gulf of Alaska, biology and oceanography. Alaska Sea Grant College Program, University of Alaska, Fairbanks, AK, p 25-34

Munns WR Jr, Gervais J, Hoffman AA, Hommen U and others (2007) Modeling approaches to population-level risk assessment. In: Barnthouse LW, Munns WR Jr, Sorensen MT (eds) Population-level ecological risk assessment. CRC Press, Boca Raton, FL, p 179-210

Norton SB, van der Schalie WH, Sergeant A, Blake-Hedges L, Wentsel R and others (2003) Ecological risk assessment: U.S. EPA's current guidelines and future directions. In: Hoffman DJ, Rattner BA, Burton GA Jr, Cairns J Jr (eds) Handbook of ecotoxicology, 2nd edn, p 951-983

NRC (National Research Council) (2003) Decline of the Steller sea lion in Alaskan waters: untangling food webs and fishing nets. National Research Council, National Academy Press, Washington, DC

Overland J, Rodionov S, Minobe S, Bond N (2008) North Pacific regime shifts: definitions, issues and recent transitions. Prog Oceanogr 77:92-102

Short JW, Maselko JM, Lindeberg MA, Harris PM, Rice SD (2006) Vertical distribution and probability of encountering intertidal Exxon Valdez oil on shorelines of three embayments within Prince William Sound, Alaska. Environ Sci Technol 40:3723-3729

Stabeno PJ, Bond NA, Hermann AJ, Kachel NB, Mordy CW, Overland JE (2004) Meteorology and oceanography of the Northern Gulf of Alaska. Cont Shelf Res 24:859-897

Editorial responsibility: Christine Paetzold, Oldendorf/Luhe, Germany; Charles Peterson, Morehead City, North Carolina, USA
Suter GW II (2007) Ecological risk assessment. 2nd edn. CRC Press, Boca Raton, FL

Taylor E, Reimer D (2008) Oil persistence on beaches in Prince William Sound - a review of SCAT surveys conducted from 1989 to 2002. Mar Pollut Bull 56:458-474

Trites AW, Miller AJ, Maschner HDG, Alexander MA and others (2007) Bottom-up forcing and the decline of Steller sea lions (Eumetopias jabatus) in Alaska: assessing the ocean climate hypothesis. Fish Oceanogr 16:46-67

USEPA (US Environmental Protection Agency) (1992) Framework for ecological risk assessment. EPA/630/R92/001. USEPA Risk Assessment Forum, Washington, DC (http://rais.ornl.gov/documents/FRMWRK_ERA.PDF)

USEPA (1998) Guidelines for ecological risk assessment. EPA/630/R-95/002F. USEPA Risk Assessment Forum, Washington, DC (www.epa.gov/raf/publications/pdfs/ ECOTXTBX.PDF)

USEPA (2005) Guidance for developing ecological soil screening levels. OSWER Directive 9285.7-55. USEPA Office of Solid Waste and Emergency Response, Washington, DC

USEPA (2007) Ecological soil screening levels for polycyclic aromatic hydrocarbons. Interim final. OSWER Directive 9285.7-78. USEPA Office of Solid Waste and Emergency Response, Washington, DC

USEPA (2010) Causal Analysis/Diagnosis Decision Information System (CADDIS). USEPA Office of Research and Development, Washington, DC (www.epa.gov/caddis)

USFWS (US Fish and Wildlife Service) (2005) Endangered and threatened wildlife and plants; determination of threatened status and special rule for the Southwest Alaska distinct population segment of the Northern Sea Otter (Enhydra lutris kenyoni). Final Rule. 50 CFR Part 17. Federal Reg 70 FR 46366, Government Printing Office, Washington, DC

Vos DJ, Quakenbush LT, Mahoney BA (2006) Documentation of sea otters and birds as prey for killer whales. Mar Mamm Sci 22:201-205

Williams TM, Estes JA, Doak DF, Springer AM (2004) Killer appetites: assessing the role of predators in ecological communities. Ecology 85:3373-3384

Submitted: August 31, 2012; Accepted: July 31, 2013

Proofs received from author(s): August 1, 2013 